\title{
O MAGMATISMO PALEOPROTEROZÓICO DA REGIÃO DE SÃO FÉLIX DO XINGU, PROVÍNCIA ESTANIFERA DO SUL DO PARÁ: PETROGRAFIA E GEOCRONOLOGIA
}

\author{
SABRINA CRISTINA CORDOVIL PINHO ${ }^{1,2}$, CARLOS MARCELLO DIAS FERNANDES ${ }^{1,3}$, \\ NILSON PINTO TEIXEIRA (IN MEMORIAM), ANTÔNIO LIMA DE PAIVA JÚNIOR ${ }^{1,4}$, \\ VANESSA LOBATO CRUZ ${ }^{4}$, CLAUDIO NERY LAMARÃO ${ }^{1,5}$ \\ \& CANDIDO AUGUSTO VELOSO MOURA ${ }^{5,6}$
}

\begin{abstract}
Resumo Novos dados petrográficos e geocronológicos são apresentados para três corpos graníticos da Suíte Intrusiva Velho Guilherme, bem como vulcanitos do Grupo Uatumã ocorrentes nas circunvizinhanças do município de São Félix do Xingu, Província Estanífera do Sul do Pará. A caracterização faciológica revelou grandes similaridades entre os maciços Serra da Queimada, Santa Rosa e Porfirítico de Vila Santa Rosa, reforçando os resultados de outros estudos em outros corpos dessa suíte. As rochas vulcânicas do Grupo Uatumã constituem uma suíte bimodal intimamente associadas a esses maciços. Idades de cristalização $\mathrm{Pb}$ $\mathrm{Pb}$ em zircão de aproximadamente 1880 Ma para essas rochas apontam para um magmatismo vulcano-plutônico exclusivamente Paleoproterozóico.
\end{abstract}

Palavras-chave: petrografia, granitos estaníferos, Tipo-A, Paleoproterozóico, Cráton Amazônico.

Abstract PALEOPROTEROZOIC MAGMATISM IN THE SÃO FÉLIX DO XINGU REGION, SOUTH PARÁ TIN PROVINCE: PETROGRAPHY AND GEOCHRONOLOGY. New petrographical and geochronological data are presented for three granitics bodies of the Velho Guilherme Intrusive Suite and for the Uatumã Group volcanic rocks, which occur around São Félix do Xingu town, Southern Pará Tin Province. The faciological characterization of these rocks reveals remarkable similarities among the Serra da Queimada, Santa Rosa, and Vila Santa Rosa porphyritic massifs, strengthening the results of other studies on other bodies of this suite. The volcanic rocks of the Uatumã Group represent a bimodal suite closely associated with these massifs. $\mathrm{Pb}-\mathrm{Pb}$ zircon ages of approximately 1880 Ma for these rocks point to an exclusively Paleoproterozoic volcano-plutonic magmatism.

Keywords: petrography, tin-bearing granite, A-type, Paleoproterozoic, Amazonian Craton

INTRODUÇÃO A evolução paleoproterozóica do Cráton Amazônico é marcada por extenso magmatismo de natureza predominantemente anorogênica, representado por um grande volume de rochas plutônicas intermediárias a félsicas, subordinadamente máficas, bem como por vulcanitos intermediários e félsicos (Bettencourt et al. 1999, Lamarão et al. 2002, Teixeira et al. 1998, Dall'Agnol et al. 1999, Teixeira et al. 2002a, Teixeira 1999).

Nas circunvizinhanças do município de São Félix do Xingu, centro-sul do estado do Pará, ocorrem diversos maciços graníticos e corpos de greisens a eles associados, alguns desses portadores de apreciáveis concentrações de cassiterita e, subordinadamente, molibdenita e wolframita (Abreu \& Ramos 1974, Teixeira 1999, Macambira \& Vale 1996, Dall'Agnol 1980), além de ampla cobertura de rochas vulcânicas intermediárias e félsicas pertencentes ao Grupo Uatumã (Macambira \& Vale 1996, Teixeira et al. 2002b, Fernandes 2005). Tais corpos graníticos encontram-se reunidos na Suíte Intrusiva Velho Guilherme (Macambira \& Vale 1996, Teixeira 1999, Teixeira et al. 2002a) e formam parte da Província Estanífera do Sul do Pará (Abreu \& Ramos 1974).

Apesar da evolução do conhecimento nos últimos anos, alguns maciços desta suíte ainda não mereceram estudos de detalhe, como por exemplo, o Maciço Serra da Queimada (Macambira \& Vale 1996). Recentemente, pequenos corpos de granitos porfiríticos foram identificados na região e denominados de Ma- ciço Santa Rosa e Maciço Porfirítico de Vila Santa Rosa, todos intimamente associados às vulcânicas félsicas do Grupo Uatumã (Fernandes 2005)

Este trabalho visa contribuir para a geologia da região de São Félix do Xingu e do Cráton Amazônico como um todo, por meio da apresentação de novos dados petrográficos e geocronológicos desses corpos graníticos, bem como de vulcanitos do Grupo Uatumã (Figura 1).

CONTEXTO GEOLÓGICO REGIONAL A área de ocorrência dessas unidades faz parte da Província Mineral de Carajás, situada no contexto do Cráton Amazônico (Almeida et al. 1981), no domínio geocronológico da Província Amazônia Central (Tassinari \& Macambira 1999) ou Carajás (Santos et al. 2000).

Em parte dessa região atuaram eventos termo-tectônicos desenvolvidos no Arqueano e no Proterozóico, os quais estão testemunhados por transformações mineralógicas e elementos estruturais impressos em unidades lito-estratigráficas arqueanas pertencentes ao Terreno Granito-Greenstone do Sul do Pará e ao Cinturão de Cisalhamento Itacaiúnas (Araújo et al. 1988, Macambira \& Vale 1996).

ASPECTOS GEOLÓGICOS E PETROGRÁFICOS A Suíte Intrusiva Velho Guilherme representa um típico magmatismo granítico anorogênico, formada por leucogranitos ex-

1 - Grupo de Pesquisa Petrologia de Granitóides (GPPG) do Centro de Geociências - UFPA. Centro de Geociências da Universidade Federal do Pará, Caixa Postal 1611. CEP 66075-900. Belém, Pará, email: spinhogeo@hotmail.com. 2 - Curso de Pós-Graduação em Geologia e Geoquímica do Centro de Geociências - UFPA.

3 - Programa de Pós-graduação em Mineralogia e Petrologia do Instituto de Geociências - USP. email:cmdf@usp.br

4 - Aluno(a) de Graduação em Geologia da UFPA. email: vanessacruz@ufpa.br, email: alpj007@hotmail.com

5 - Departamento de Geoquímica e Petrologia do Centro de Geociências - UFPA. email: lamarão@ufpa.br

6 - Laboratório de Geologia Isotópica (Pará-Iso) do Centro de Geociências - UFPA. email: candido@ufpa.br 


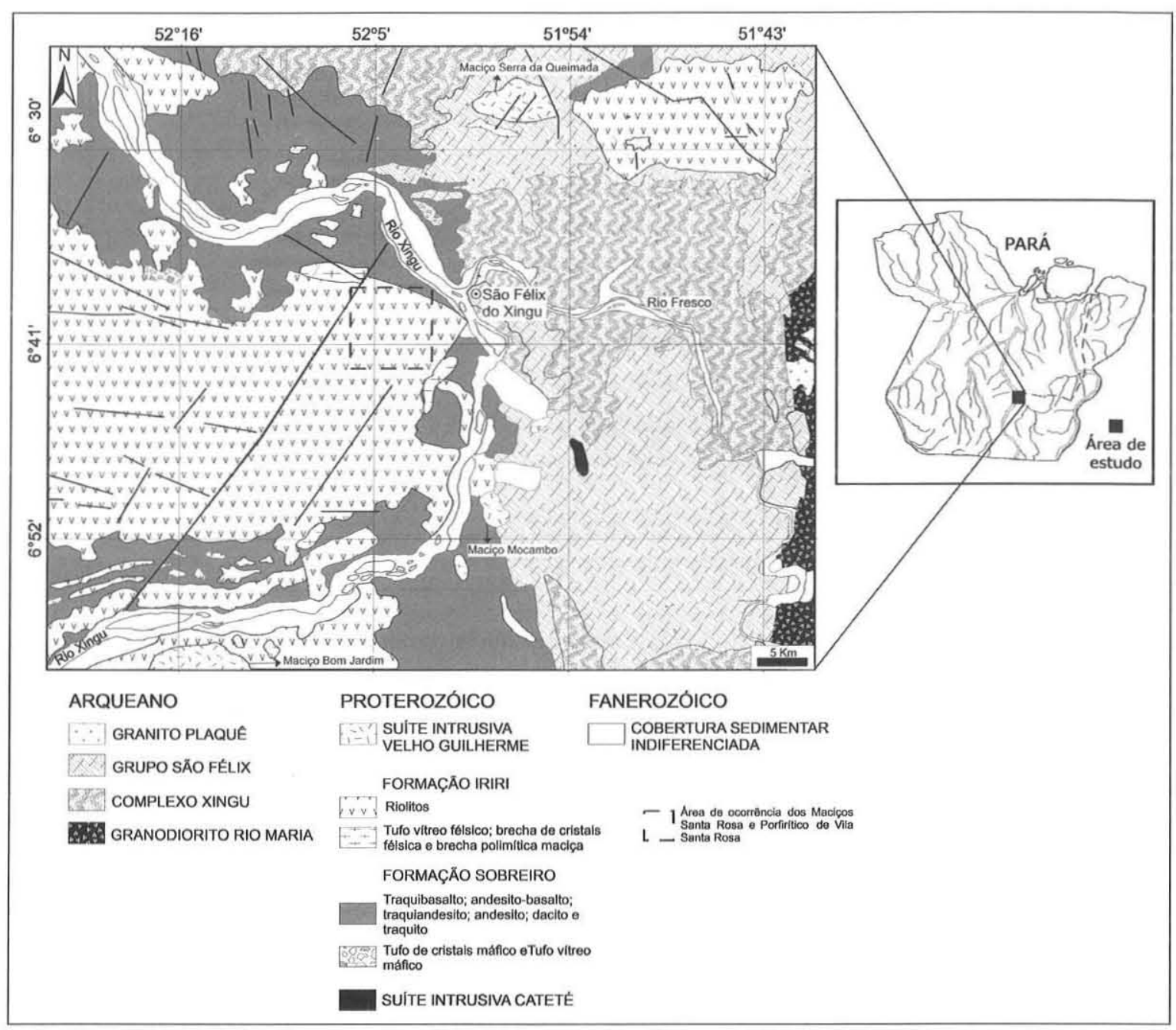

Figura 1 - Mapa geológico da Folha SB-22-Y-B (São Félix do Xingu), mostrando a distribuição dos maciços graníticos da Suite Intrusiva Velho Guilherme e das vulcânicas do Grupo Uatumã (Fernandes 2005).

tremamente evoluídos. Fazem parte dela os granitos Antônio Vicente, Velho Guilherme, Mocambo, Rio Xingu, Ubim/Sul, Ubim/Norte, Serra da Queimada e Bom Jardim. Tais maciços apresentam composição álcali-feldspato granítica, sienogranítica e, subordinadamente, monzogranítica, e se mostram afetados por alterações pós-magmáticas em diferentes intensidades. Exibem características geoquímicas peraluminosas a metaluminosas e feições de granitóides tipo-A (Collins et al. 1982, Loiselle \& Wones 1979, Teixeira et al. 2002a), bem como afinidade geoquímica intraplaca (Pearce et al. 1984, Teixeira et al. 2002a).

O Grupo Uatumã é constituído por amplo vulcanismo efusivo e explosivo, evidenciado por: derrames de lavas coerentes de composições traquibasáltica, andesito-basáltica, traquiandesítica, andesítica, dacítica, traquítica e riolítica; depósitos de fluxo piroclástico, representados por tufo de cristais máfico, tufo vítreo máfico, tufo vítreo félsico e brecha polimítica maciça (Fernandes 2005). O vulcanismo básico-intermediário, reconhecido como Formação Sobreiro, tem afinidade geoquímica de arcovulcânico e caráter cálcico-alcalino transicional entre alto-K e shoshonítico. Por sua vez, o ácido é transicional entre subalcalno e alcalino e tem assinatura geoquímica intraplaca, denominado de Formação Iriri (Macambira \& Vale 1996, Fernandes 2005, Teixeira et al. 2002b).

Maciço Serra da Queimada (MSQ) Pinho (2005) distinguiu no interior do maciço dois domínios petrográficos principais
(Figura 2): I - biotita-monzogranito, moderadamente afetado por alterações pós-magmáticas, evidenciadas pelo desenvolvimento de clorita, epídoto, sericita e, subordinadamente, fluorita; 2 - biotita-sienogranito, com o par sericita-muscovita sendo o principal produto de alteração pós-magmática. A relação temporal entre essas fácies, bem como suas distribuições espaciais, não puderam ser deduzidas devido à falta de afloramentos.

Apesar das variações composicionais, os granitos que constituem o MSQ guardam muitas similaridades. São isotrópicos, apresentam estrutura maciça, textura fanerítica fina a média, e coloração variando de rosa-acinzentada a cinza levemente esverdeada, exibindo localmente vênulas milimétricas que seccionam a rocha em diversas direções, indicando, muito provavelmente, a movimentação de fluídos posteriores a sua cristalização. Seu conteúdo de minerais máficos é relativamente baixo ( $\mathrm{M}^{\prime}<20 \%$ ), impondo seu caráter leucocrático e silicoso (Figura 2). São formados essencialmente por plagioclásio, feldspato potássico pertítico e quartzo. As bandas sódicas das pertitas, originadas por processos de exsolução (em cordões ou filmes) e de espessamento (em bandas, veios e manchas), por vezes, associadas com substituição (cf Smith \& Brown 1988), são abundantes. Intercrescimentos granofíricos estão comumente presentes. Apatita, zircão, opacos e titanita figuram como acessórios primários. A biotita, única fase varietal, apresenta-se como cristais anédricos de granulação fina a média, parcialmente cloritizada. Apresenta inclusões de minerais opacos. 


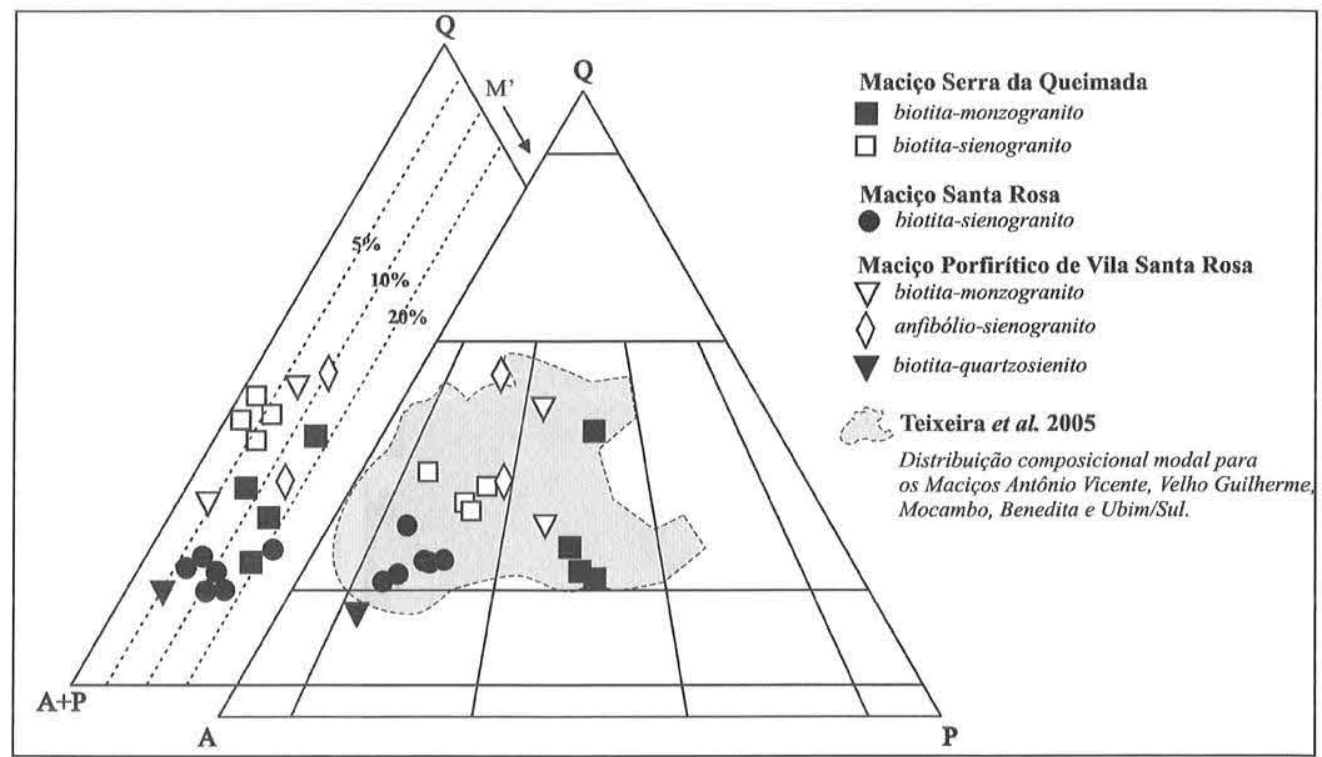

Figura 2 - Diagramas triangulares $Q-A-P$ e Q-A+P-M'(Streckeisen 1976), mostrando a composição modal dos Maciços Serra da Queimada, Santa Rosa e Porfirítico de Vila Santa Rosa.

Maciço Santa Rosa (MSR) Ocorre associado aos riolitos da Formação Iriri, imediatamente a sudeste de São Félix do Xingu. Relações de campo sugerem contemporaneidade entre essas duas unidades, pois foram identificados encraves do MSR no primeiro e vice-versa, caracterizando textura de mingling (Fernandes 2005). Os estudos petrográficos indicaram que o MSR é homogêneo e não apresenta variações composicionais e texturais significativas, sendo caracterizado apenas o domínio petrográfico biotita-sienogranito (Figura 2). A rocha tem textura porfirítica, caracterizada por fenocristais euédricos a anédricos de quartzo, feldspato potássico e plagioclásio de dimensões variáveis, imersos em uma matriz hipidiomórfica heterogranular fina a média, constituída essencialmente de quartzo, feldspato potássico e plagioclásio. Exibe aspecto maciço e coloração vermelho-tijolo. Microscopicamente ostenta essencialmente fenocristais de quartzo, feldspato potássico e plagioclásio imersos em matriz quartzo-feldspática, localmente granofírica. A biotita figura como varietal, ocorrendo como restos. Como fases acessórias primárias comparecem zircão, monazita, apatita e minerais opacos. Representam as fases secundárias, ligadas a processos de alteração hidrotermal pós-magmática, sericita, muscovita, epídoto, carbonatos, albita intergranular e clorita.

Maciço Porfirítico de Vila Santa Rosa (MPSR) Ocorre como pequenos blocos nos arredores de São Félix do Xingu identificou três domínios petrográficos principais: 1 - biotita-monzogranito; mostra-se fracamente afetado por alterações tardi à pós-magmáticas, evidenciado pelo desenvolvimento de clorita, muscovita, sericita e epídoto, sendo este último pouco comum. É constituindo essencialmente por quartzo, feldspato potássico e plagioclásio, anédricos, envoltos por matriz felsofírica de granulação fina à média, localmente granofírica. A biotita figura como mineral varietal. Apatita, minerais opacos e zircão figuram como principais acessórios primários; 2 - anfibólio-sienogranito, exibe moderado a avançado estágio de alteração quando comparado às rochas monzograníticas anteriores, representado por fluorita, clorita, epídoto, muscovita, sericita e minerais opacos. É composto de quartzo, feldspato potássico e plagioclásio, euédricos à anédricos, imersos em matriz felsofírica fina com intercrescimentos micrográficos do tipo cuneiforme, embora possa ocorrer também o tipo insular, com o anfibólio comparecendo como varietal. Como fases acessórias primárias estão presentes zircão e apatita; 3 - biotita-quartzosienito, encontra-se intensamente afetado por alterações tardi a pós-magmáticas, evidenciada por epídoto, muscovita, sericita e clorita. É constituída essencialmente por quartzo, feldspato potássico e plagioclásio. Como mineral varietal ocorre biotita. Opacos e zircão são minerais acessórios primários.

A exemplo do MSQ, bem como do Maciço Rio Xingu (Teixeira 1999), o MPSR mostra grandes similaridades entre as fácies identificadas, apesar das variações composicionais aferidas. No geral, em escala macroscópica, são rochas de isotrópicas, de textura porfirítica caracterizadas pela presença de fenocristais de quartzo, feldspato potássico e plagioclásio, imersos em matriz afanítica de coloração variável desde marrom-avermelhada a rosa-amarronzada. Intercrescimento granofírico é uma feição comum às três fácies. $\mathrm{O}$ conteúdo de máficos nessas rochas raramente chega a $20 \%$. A Figura 2 exibe a distribuição composicional do MPSR, bem como o teor de máficos.

Vulcânicas do Grupo Uatumã As lavas da Formação Sobreiro apresentam aspecto maciço, texturas porfirítica e afanítica e coloração variável, desde negra, cinza-escuro a verde-escuro. Ao microscópio, trata-se de termos com textura microporfirítica a microglomeroporfirítica, ora holocristalina ora hipocristalina, apresentando microfenocristais de plagioclásio, clinopiroxênio e anfibólio, imersos em matriz criptocristalina, microlítica (predominantemente plagioclásio) ou esferulítica. Subordinadamente ocorrem litotipos afíricos constituídos por esferulitos dos tipos "esférico", "leque" e "nó de gravata" (cf McPhie et al. 1993) formados pelo intercrescimento em fibras de anfibólio. Sericita, clorita, epídoto e carbonatos são fases secundárias. Localmente ocorrem amídalas esféricas à sub-esféricas originadas por processo de degaseificação, as quais se encontram preenchidas a partir do centro por clorita, epídoto e carbonatos. Zircão, apatita e minerais opacos ocorrem como acessórios primários. Os litotipos piroclásticos apresentam textura piroclástica caracterizada por grande quantidade de cristais e fragmentos de cristais de quartzo e plagioclásio mal selecionados, bem como fragmentos líticos de composição intermediária e vítrea (glassy shar$d s$ ) e pumices intensamente vesiculados, suportados por matriz 
vitrofirica. Localmente, desenvolvem fraturas, as quais podem estar preenchidas por material de natureza hidrotermal a base de quartzo, epídoto, clorita e carbonato. Esses mesmos produtos podem também ocorrer como fases minerais associadas à alteração hidrotermal pervasiva que afetou essas rochas em diferentes graus (Fernandes 2005).

As lavas que constituem a Formação Iriri mostram também aspecto maciço, texturas porfirítica e afanítica e coloração variável desde rosa-claro, rosa-avermelhado a rosa-escuro. As variedades porfiríticas ostentam fenocristais milimétricos de quartzo, plagioclásio e feldspato potássico envoltos por matriz afanítica. Microscopicamente são caracterizadas por textura porfirítica holocristalina e matriz felsofirica (mosaico de quartzo e feldspato potássico), criptocristalina ou esferulítica e, localmente, granofírica. Clorita, epídoto, carbonatos e sericita são minerais secundários. Zircão e minerais opacos são fases acessórias primárias. Em relação aos termos piroclásticos, estão presentes tufos com textura piroclástica caracterizada por cristais e fragmentos de cristais de anfibólio e, subordinadamente, plagioclásio, bem como fragmentos líticos de composições félsica e intermediária suportados por matriz vitrofírica. Em menor proporção ocorrem brechas maciças contendo fragmentos centimétricos de várias litologias, suportados por matriz vitrofirica. Sericita, carbonatos e minerais opacos apresentam-se como fases secundárias (Fernandes 2005).

GEOCRONOLOGIA A geocronologia foi realizada no Laboratório de Geologia Isotópica (Pará-Iso) do Centro de Geociências da UFPA. Para tal, foi empregado o método de evaporação de $\mathrm{Pb}$ em zircão por termoionização, cujos princípios básicos foram desenvolvidos por $\operatorname{Kober}(1986,1987)$ e sua adaptação ao Pará-Iso discutida por Gaudette et al. (1998, 1993). Os cristais foram extraídos das amostras utilizando-se o método clássico de separação de minerais pesados, que envolve a trituração, pulverização, elutriação, separação magnética e aplicação de bromofórmio.

A determinação da idade dos cristais de zircão selecionados foi realizada em um espectrômetro de massa marca FINNIGAN, modelo MAT-262. Este equipamento utiliza filamentos duplos de rênio, sendo um de ionização e outro de evaporação, técnica que proporciona a emissão do sinal de $\mathrm{Pb}$ estável durante um longo período de tempo (Kober 1986). As análises envolveram o aquecimento gradativo dos cristais de zircão em etapas de 1450 $\circ, 1500^{\circ} \mathrm{e} 1550^{\circ} \mathrm{C}$, e posterior determinação de idade para cada uma. A idade final de cada amostra foi a média dos resultados obtidos a temperaturas mais elevadas de todos os cristais analisados. As correções para o chumbo comum $\left({ }^{204} \mathrm{~Pb}\right)$ foram realizadas por intermédio do modelo de Stacey \& Kramers (1975). As médias ponderadas e os erros nas idades, em nível $2 \sigma$, foram calculados seguindo-se o método de Gaudette et al. (1998).

Maciço Serra da Queimada Foram selecionadas as amostras NC-SQ-22 e NC-SQ-8, correspondentes, respectivamente, as fácies biotita-sienogranito e biotita-monzogranito. Na primeira, constatou-se que os cristais de zircão apresentavam elevado grau de metamictização e muitas fraturas. Entretanto, por não se dispor de outros com melhor qualidade, sete grãos foram coletados para análise. Os grãos 2, 4, 5 e 7 foram excluídos do cálculo por possuírem razões ${ }^{204} \mathrm{~Pb} /{ }^{206} \mathrm{~Pb}$ maiores que $4 \times 10^{-4}$. Os cristais $1 \mathrm{e}$ 8 apresentaram idades de $20754 \pm 4$ Ma e $2159 \pm 25$ Ma, respectivamente, em uma única etapa de evaporação cada, o que não garante resultado confiável, pois certamente teriam idades mais antigas nas etapas de temperaturas mais elevadas. O grão 6 revelou idade $2545 \pm 9 \mathrm{Ma}$, sugerindo contaminação/contribuição de rochas arqueanas na formação deste maciço. A amostra NCSQ-08 forneceu cristais comparativamente mais bem preserva-

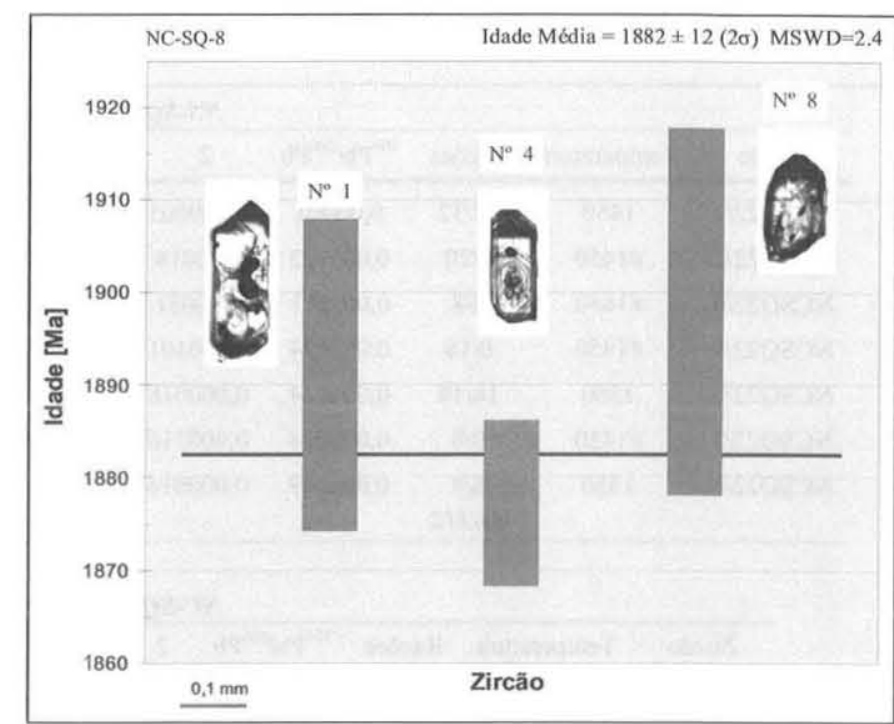

Figura 3 - Diagrama de barras mostrando a média das idades de três cristais de zircão da amostra NC-SQ-8 do MSQ.

dos. Dos seis grãos selecionados, três apresentaram resultados satisfatórios (Figura 3) e definiram idade média ${ }^{207} \mathrm{~Pb} /{ }^{206} \mathrm{~Pb}$ de $1882 \pm 12 \mathrm{Ma}$, considerada a idade de cristalização do maciço. Os outros três cristais foram excluídos do cálculo por apresentarem razões ${ }^{204} \mathrm{~Pb} /{ }^{206} \mathrm{~Pb}$ maiores que $4 \times 10^{-4}$ (Tabela 1 ).

Maciço Santa Rosa Foram selecionadas as amostras NCGP-52 e NC-GP-49 (Figura 4). Na primeira, constatou-se que os grãos de zircão apresentavam baixo grau de metamictização e poucas fraturas, sendo, portanto, indicados para análises. Para esta primeira amostra foram selecionados seis grãos de zircão. Dentre esses, os grãos 1, 2, 3, 4 e 5 apresentaram resultados satisfatórios, definindo idade média de cristalização de $1887 \pm 2$ $\mathrm{Ma}$. O cristal 6 foi subjetivamente eliminado no processamento dos dados.

$\mathrm{Na}$ amostra NC-GP-49 foram selecionados doze grãos de zircão para análise e apenas quatro $(2,3,6$ e 11) forneceram resultados consistentes, definindo idade média de $1888 \pm 3 \mathrm{Ma}$, coincidente com aquela da amostra anterior e interpretada como idade mínima de cristalização do MSR. Os cristais 4, 8 e 10 foram automaticamente eliminados por apresentarem chumbo comum acima do limite máximo admitido $(0,0004)$. Os outros grãos foram subjetivamente eliminados por apresentarem apenas uma etapa de evaporação. Os resultados analíticos estão expostos na Tabela 2.

Maciço Porfirítico de Vila Santa Rosa Foram selecionadas as amostras NC-RX-6 e NC-RX-15 (Figura 5), relativo as fácies biotita-quartzosienito e biotita-monzogranito. Na primeira, foram coletados cinco grãos. Dentre esses, apenas o grão 3 não apresentou resultado satisfatório. A idade média de cristalização obtida do MPSR foi de $1881 \pm 3$ Ma.

Para a segunda amostra foram selecionados outros cinco grãos. Dentre esses, apenas o grão 3 não apresentou resultado satisfatório. A idade média obtida para esta amoștra foi de 1881 $\pm 2 \mathrm{Ma}$, coincidente com a da amostra anterior e interpretada como a idade mínima de cristalização do MPSR (Tabela 3).

Vulcânicas do Grupo Uatumã Duas amostras foram selecionadas para a datação da Formação Sobreiro. A primeira (NC-FS-126), referente a um traquiandesito, foi infrutífera devido às dimensões diminutas dos cristais disponíveis. Diante 
O magmatismo paleoproterozóico da região de São Félix do Xingu, província estanífera do sul do Pará: petrografia e geocronologia.

Tabela 1 - Resultados analiticos Pb-Pb em zircão das amostras NC-SQ-22 e NC-SQ-8 do MSQ.

\begin{tabular}{|c|c|c|c|c|c|c|c|c|c|c|c|c|}
\hline \multicolumn{13}{|c|}{ NS-SQ-22 - Maciço Serra da Queimada } \\
\hline Zircão & Temperatura & Razões & ${ }^{204} \mathrm{~Pb} /{ }^{206} \mathrm{~Pb}$ & $2_{-}$ & ${ }^{208} \mathrm{~Pb} /{ }^{206} \mathrm{~Pb}$ & 2 & ${ }^{207} \mathrm{~Pb} /{ }^{206} \mathrm{~Pb}$ & 2 & $\left({ }^{207} \mathrm{~Pb} /{ }^{206} \mathrm{~Pb}\right) \mathrm{c}$ & 2 & Idade & 2 \\
\hline NCSQ22/1 & 1450 & $32 / 32$ & 0,00003 & 0,000005 & 0,03389 & 0,00018 & 0,12865 & 0,00029 & 0,12827 & 0,00028 & 2075 & 4 \\
\hline NCSQ22/2 & $\# 1450$ & $0 / 20$ & 0,005922 & 0,00018 & 0,24470 & 0,0119 & 0,17965 & 0,00028 & 0,10063 & 0,00217 & 1636 & 40 \\
\hline NCSQ22/4 & $\# 1450$ & $0 / 8$ & 0,003111 & 0,00031 & 0,26223 & 0,01041 & 0,13668 & 0,00073 & 0,09408 & 0,00451 & 1510 & 91 \\
\hline NCSQ22/5 & $\# 1450$ & $0 / 16$ & 0,006674 & 0,000101 & 0,27517 & 0,00394 & 0,19078 & 0,00038 & 0,10232 & 0,00135 & 1667 & 24 \\
\hline NCSQ22/6 & 1500 & $14 / 14$ & 0,000134 & 0,000018 & 0,09616 & 0,00081 & 0,17036 & 0,00089 & 0,16866 & 0,00093 & 2545 & 9 \\
\hline NCSQ22/7 & $\# 1450$ & $0 / 8$ & 0,000624 & 0,000216 & 0,13593 & 0,01227 & 0,13879 & 0,00213 & 0,13059 & 0,00358 & 2106 & 48 \\
\hline NCSQ22/8 & 1450 & $\begin{array}{c}8 / 8 \\
54 / 112\end{array}$ & 0,000049 & 0,000014 & 0,11885 & 0,02059 & 0,13521 & 0,00194 & 0,13457 & 0,00195 & 2159 & 25 \\
\hline
\end{tabular}

NC-SQ-08 - Maciço Serra da Queimada

\begin{tabular}{|c|c|c|c|c|c|c|c|c|c|c|c|c|}
\hline Zircão & Temperatura & Razões & ${ }^{204} \mathrm{~Pb} /{ }^{206} \mathrm{~Pb}$ & 2 & ${ }^{208} \mathrm{~Pb} /{ }^{206} \mathrm{~Pb}$ & 2 & ${ }^{207} \mathrm{~Pb} /{ }^{206} \mathrm{~Pb}$ & 2 & $\left({ }^{207} \mathrm{~Pb} /{ }^{206} \mathrm{~Pb}\right) \mathrm{c}$ & 2 & Idade & 2 \\
\hline NCSQ8/1 & 1500 & $10 / 10$ & 0,000138 & 17 & 0,22003 & 634 & 0,11755 & 106 & 0,11567 & 109 & 1891 & 17 \\
\hline NCSQ8/3 & $\# 1450$ & $0 / 14$ & 0,001821 & 89 & 0,17759 & 645 & 0,10743 & 43 & 0,08178 & 175 & 1240 & 42 \\
\hline \multirow[t]{2}{*}{ NCSQ8/4 } & $* 1450$ & $0 / 14$ & 0,000348 & 16 & 0,13425 & 231 & 0,11729 & 52 & 0,11258 & 57 & 1842 & 9 \\
\hline & 1500 & $8 / 8$ & 0,000127 & 22 & 0,12942 & 113 & 0,11649 & 46 & 0,11477 & 55 & 1877 & 9 \\
\hline NCSQ8/5 & $\# 1450$ & $0 / 20$ & 0,00264 & 102 & 0,20761 & 391 & 0,13191 & 51 & 0,09548 & 191 & 1538 & 38 \\
\hline NCSQ8/6 & $\# 1450$ & $0 / 16$ & 0,001005 & 39 & 0,13215 & 81 & 0,12103 & 57 & 0,10701 & 93 & 1749 & 16 \\
\hline \multirow[t]{3}{*}{ NCSQ8/8 } & 1450 & $8 / 8$ & 0,000596 & 44 & 0,23101 & 828 & 0,12417 & 114 & 0,11615 & 129 & 1898 & 20 \\
\hline & $\# 1500$ & $0 / 8$ & 0,002353 & 49 & 0,16269 & 1681 & 0,12327 & 297 & 0,0905 & 774 & 1437 & 163 \\
\hline & & $26 / 98$ & & & & & & & \multicolumn{4}{|c|}{ Idade média $=1882 \pm 12 \mathrm{Ma}$} \\
\hline
\end{tabular}

(c) - razão ${ }^{207} \mathrm{~Pb} /{ }^{206} \mathrm{~Pb}$ corrigida do $\mathrm{Pb}$ comum; (*) - etapa de evaporação eliminada subjetivamente;

(\#) - etapa de evaporação eliminada por apresentar razão ${ }^{204} \mathrm{~Pb} /{ }^{206} \mathrm{~Pb}$ superior a 0,0004 .
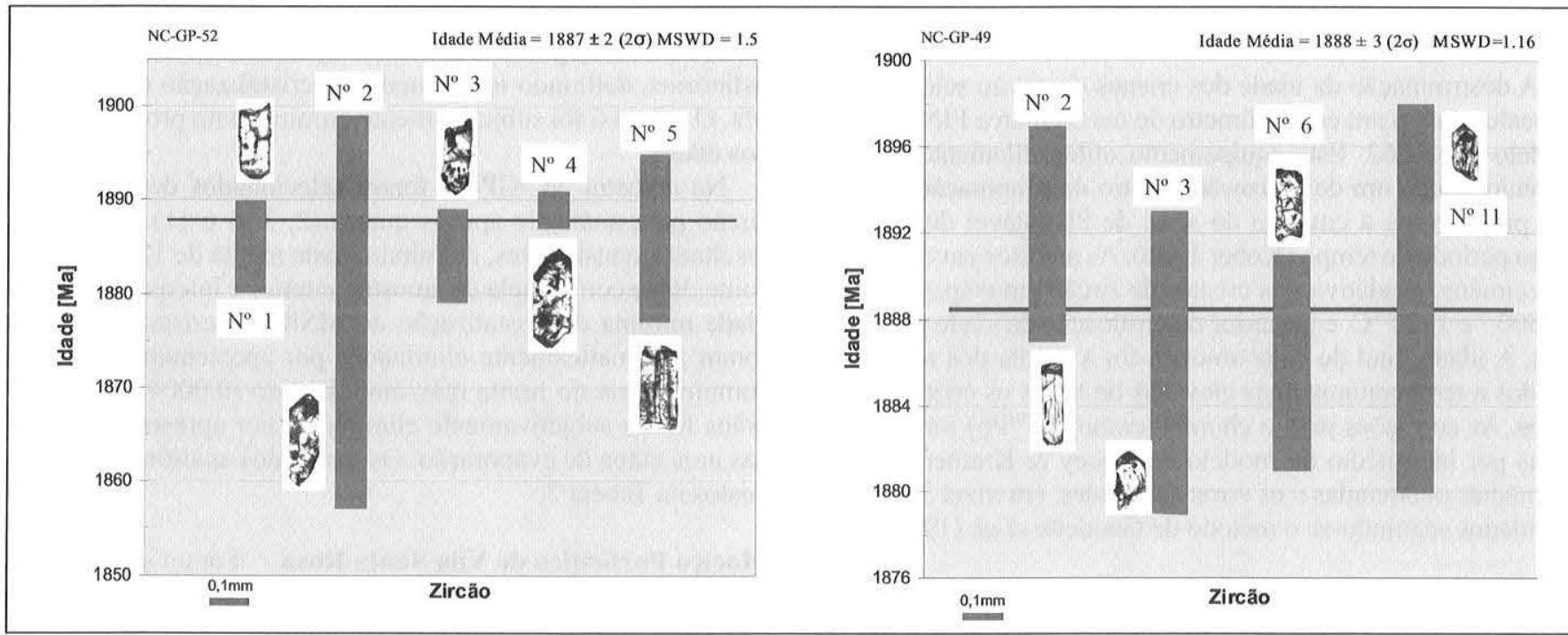

Figura 4 - Diagramas de barras mostrando a média das idades dos grãos de zircão analisados das amostras NC-GP-52 e NC-GP49 do MSR.

desse quadro, optou-se pela utilização da amostra NC-FS-38, referente a um dacito porfirítico, o qual representa o termo mais evoluído da unidade.

Dessa amostra foram selecionados 15 grãos para datação. Três cristais apresentaram razões ${ }^{204} \mathrm{~Pb} /{ }^{206} \mathrm{~Pb}$ acima de $4 \times 10^{-4} \mathrm{e}$ foram automaticamente eliminados do cálculo da idade final. Um cristal forneceu idade de $2606 \pm 4$ Ma, apontando também para contribuição/contaminação de crosta arqueana no proces- so de geração destes vulcanitos. O cristal 7 revelou na segunda etapa de aquecimento uma idade menor que na primeira e foi excluído. Outros seis grãos revelaram idades entre 1770 e 1864 $\mathrm{Ma}$, em uma ou duas etapas de aquecimento, sendo subjetivamente excluídos durante o tratamento dos dados. Os cristais 12 e 20 revelaram nas etapas de aquecimento de $1450^{\circ} \mathrm{C}$ e $1500^{\circ}$ $\mathrm{C}$ idades superpostas ao erro. Para tal, optou-se pelo cálculo da média ponderada entre as idades das etapas obtidas para cada 
Tabela 3 - Resultados analiticos Pb-Pb em zircão do MPSR - Amostras NC-RX-6 e NC-RX-15.

NC-RX-6 - Maciço Porfirítico de Vila Santa Rosa

\begin{tabular}{|c|c|c|c|c|c|c|c|c|c|c|c|c|}
\hline Zircão & Temperatura & Razões & ${ }^{204} \mathrm{~Pb} /{ }^{206} \mathrm{~Pb}$ & 2 & ${ }^{208} \mathrm{~Pb} /{ }^{206} \mathrm{~Pb}$ & 2 & ${ }^{207} \mathrm{~Pb} /{ }^{206} \mathrm{~Pb}$ & 2 & $\left({ }^{207} \mathrm{~Pb} /{ }^{206} \mathrm{~Pb}\right) \mathrm{c}$ & 2 & Idade & 2 \\
\hline \multirow[t]{2}{*}{ NCRX6/1 } & $\# 1450$ & $0 / 8$ & 0,00054 & 16 & 0,15578 & 91 & 0,12181 & 71 & 0,11454 & 77 & 1873 & 91 \\
\hline & 1500 & $30 / 30$ & 0,00035 & 4 & 0,15433 & 67 & 0,12015 & 63 & 0,11517 & 35 & 1883 & 5 \\
\hline \multirow[t]{2}{*}{ NCRX6/2 } & 1450 & $30 / 30$ & 0,000074 & 8 & 0,15279 & 72 & 0,11612 & 51 & 0,11528 & 55 & 1885 & 9 \\
\hline & 1500 & $30 / 30$ & 0,000074 & 9 & 0,14599 & 07 & 0,11605 & 34 & 0,11504 & 42 & 1881 & 7 \\
\hline \multirow{2}{*}{ NCRX6/3 } & \#1500 & $0 / 8$ & 0,002459 & 18 & 0,06668 & 57 & 0,11973 & 25 & 0,08555 & 93 & 1328 & 38 \\
\hline & $* 1450$ & $0 / 8$ & 0,000023 & 2 & 0,15569 & 02 & 0,11401 & 01 & 0,11370 & 29 & 1860 & 5 \\
\hline NCRX6/4 & 1500 & $12 / 12$ & 0,000107 & 52 & 0,14694 & 36 & 0,11633 & 96 & 0,11476 & 35 & 1876 & 6 \\
\hline \multirow{3}{*}{ NCRX6/5 } & $* 1450$ & $0 / 6$ & 0,000109 & 18 & 0,13298 & 24 & 0,11947 & 87 & 0,11801 & 41 & 1927 & 62 \\
\hline & 1500 & $38 / 38$ & 0,000194 & 1 & 0,13237 & 35 & 0,11706 & 19 & 0,11518 & 42 & 1883 & 6 \\
\hline & & $140 / 170$ & & & & & & & \multicolumn{4}{|c|}{ Idade média $=1881 \pm 3 \mathrm{Ma}$} \\
\hline
\end{tabular}

NC-RX-15 - Maciço Porfirítico de Vila Santa Rosa

\begin{tabular}{|c|c|c|c|c|c|c|c|c|c|c|c|c|}
\hline Zircão & Temperatura & Razões & ${ }^{204} \mathrm{~Pb} /{ }^{206} \mathrm{~Pb}$ & 2 & ${ }^{208} \mathrm{~Pb} /{ }^{206} \mathrm{~Pb}$ & 2 & ${ }^{207} \mathrm{~Pb} /{ }^{206} \mathrm{~Pb}$ & 2 & $\left({ }^{207} \mathrm{~Pb} /{ }^{206} \mathrm{~Pb}\right) \mathrm{c}$ & 2 & Idade & 2 \\
\hline \multirow[t]{2}{*}{ NCRX15/1 } & $* 1450$ & $0 / 8$ & 0,000052 & 12 & 0,22098 & 545 & 0,11487 & 61 & 0,11417 & 63 & 1867 & 10 \\
\hline & 1480 & $26 / 32$ & 0,000030 & 4 & 0,22124 & 58 & 0,11536 & 31 & 0,11490 & 27 & 1879 & 4 \\
\hline \multirow[t]{2}{*}{ NCRX $15 / 2$} & $* 1450$ & $0 / 24$ & 0,000174 & 29 & 0,18170 & 14 & 0,11158 & 35 & 0,10934 & 43 & 1789 & 7 \\
\hline & 1500 & $36 / 36$ & 0,000028 & 4 & 0,23693 & 104 & 0,11539 & 19 & 0,11499 & 22 & 1880 & 4 \\
\hline \multirow[t]{3}{*}{ NCRX $15 / 3$} & $\# 1450$ & $0 / 6$ & 0,032747 & 66 & 0,70626 & 35 & 0,57723 & 77 & 0,33633 & 82 & 3647 & 17 \\
\hline & $\# 1500$ & $0 / 36$ & 0,000678 & 8 & 0,22387 & 22 & 0,12471 & 45 & 0,11562 & 02 & 1890 & 3 \\
\hline & $\# 1550$ & $0 / 10$ & 0,000749 & 13 & 0,24775 & 03 & 0,12538 & 49 & 0,11524 & 03 & 1884 & 5 \\
\hline \multirow[t]{2}{*}{ NCRX $15 / 4$} & $* 1500$ & $0 / 34$ & 0,000047 & 03 & 0,19044 & 68 & 0,11450 & 32 & 0,11391 & 04 & 1863 & 6 \\
\hline & 1550 & $16 / 16$ & 0,000093 & 18 & 0,19406 & 23 & 0,11639 & 34 & 0,11508 & 06 & 1882 & 9 \\
\hline \multirow[t]{3}{*}{ NCRX $15 / 5$} & $\# 1450$ & $0 / 20$ & 0,001205 & 04 & 0,21867 & 32 & 0,13140 & 29 & 0,11519 & 04 & 1883 & 7 \\
\hline & 1500 & $36 / 36$ & 0,000208 & 06 & 0,24944 & 61 & 0,11802 & 17 & 0,11517 & 02 & 1883 & 3 \\
\hline & & $114 / 258$ & & & & & & & \multicolumn{4}{|c|}{ Idade média $=1881 \pm 2 \mathrm{Ma}$} \\
\hline
\end{tabular}

(c) - razão ${ }^{207} \mathrm{~Pb} /{ }^{206} \mathrm{~Pb}$ corrigida do $\mathrm{Pb}$ comum; $(*)$ - etapa de evaporação eliminada subjetivamente;

(\#) - etapa de evaporação eliminada por apresentar razão ${ }^{204} \mathrm{~Pb} /{ }^{206} \mathrm{~Pb}$ superior a 0,0004 .

Tabela 4 - Resultados analíticos Pb-Pb em zircão de um dacito porfirítico (amostra NC-FS-38) da Formação Sobreiro.

\begin{tabular}{|c|c|c|c|c|c|c|c|c|c|c|c|c|}
\hline \multicolumn{13}{|c|}{ NC-FS-38 - Formação Sobreiro (Grupo Uatumã) } \\
\hline Zircão & Temperatura & Razões & ${ }^{204} \mathrm{~Pb} /{ }^{206} \mathrm{~Pb}$ & 2 & ${ }^{208} \mathrm{~Pb} /{ }^{206} \mathrm{~Pb}$ & 2 & ${ }^{207} \mathrm{~Pb} /{ }^{206} \mathrm{~Pb}$ & 2 & $\left({ }^{207} \mathrm{~Pb} /{ }^{206} \mathrm{~Pb}\right) \mathrm{c}$ & 2 & Idade & 2 \\
\hline NCFS38/1 & $\# 1450$ & $0 / 26$ & 0,000957 & 0,000063 & 0,08886 & 0,0023 & 0,11278 & 0,0012 & 0,10022 & 0,00109 & 1628 & 20 \\
\hline \multirow[t]{2}{*}{ NCFS38/2 } & $* 1450$ & $0 / 30$ & 0,00012 & 0,000007 & 0,12046 & 0,00049 & 0,13426 & 0,00055 & 0,13252 & 0,00057 & 2132 & 7 \\
\hline & $* 1500$ & $0 / 30$ & 0,000056 & 0,000009 & 0,12365 & 0,00039 & 0,1758 & 0,00053 & 0,17502 & 0,00043 & 2606 & 4 \\
\hline NCFS38/3 & $* 1450$ & $0 / 32$ & 0,000382 & 0,000023 & 0,09457 & 0,00103 & 0,11566 & 0,00117 & 0,11037 & 0,00138 & 1806 & 23 \\
\hline NCFS38/4 & $\# 1450$ & $0 / 30$ & 0,001099 & 0,00003 & 0,12059 & 0,0015 & 0,12661 & 0,00079 & 0,11138 & 0,00053 & 1822 & 9 \\
\hline NCFS38/5 & $* 1450$ & $0 / 40$ & 0,000082 & 0,000008 & 0,09383 & 0,00095 & 0,11481 & 0,00015 & 0,11377 & 0,00022 & 1861 & 3 \\
\hline NCFS38/6 & $* 1450$ & $0 / 16$ & 0,000092 & 0,000057 & 0,12984 & 0,00523 & 0,11335 & 0,00067 & 0,11204 & 0,00058 & 1833 & 9 \\
\hline \multirow[t]{2}{*}{ NCFS38/7 } & $* 1450$ & $0 / 24$ & 0,000092 & 0,000022 & 0,06243 & 0,00126 & 0,13292 & 0,00065 & 0,13185 & 0,00053 & 2123 & 7 \\
\hline & $* 1500$ & $0 / 38$ & 0,00004 & 0,000011 & 0,03926 & 0,00043 & 0,12904 & 0,00017 & 0,1285 & 0,00017 & 2078 & 2 \\
\hline NCFS38/10 & $* 1450$ & $0 / 36$ & 0,000206 & 0,000007 & 0,15318 & 0,00194 & 0,11119 & 0,00025 & 0,1082 & 0,00037 & 1770 & 6 \\
\hline \multirow[t]{2}{*}{ NCFS38/11 } & $* 1450$ & $0 / 34$ & 0,000118 & 0,000004 & 0,13334 & 0,00154 & 0,11269 & 0,00021 & 0,11112 & 0,00017 & 1818 & 3 \\
\hline & $* 1500$ & $0 / 6$ & 0,000026 & 0,000032 & 0,10011 & 0,00136 & 0,11525 & 0,00055 & 0,1149 & 0,0007 & 1879 & 11 \\
\hline \multirow[t]{2}{*}{ NCFS38/12 } & $* 1450$ & $0 / 30$ & 0,000147 & 0,00002 & 0,0952 & 0,00139 & 0,11641 & 0,00058 & 0,11444 & 0,00082 & 1871 & 13 \\
\hline & 1500 & $32 / 32$ & 0,000051 & 0,000007 & 0,08481 & 0,0003 & 0,11602 & 0,0003 & 0,11539 & 0,00029 & 1886 & 4 \\
\hline \multirow[t]{2}{*}{ NCFS $38 / 20$} & $* 1450$ & $0 / 16$ & 0,000063 & 0,000019 & 0,11513 & 0,00094 & 0,1154 & 0,00074 & 0,11456 & 0,00078 & 1873 & 12 \\
\hline & 1500 & $30 / 30$ & 0,000039 & 0,000008 & 0,10201 & 0,00049 & 0,11569 & 0,00034 & 0,11529 & 0,00039 & 1885 & 6 \\
\hline NCFS38/21 & $* 1450$ & $0 / 8$ & 0 & 0 & 0,10194 & 0,00144 & 0,11706 & 0,00263 & 0,11706 & 0,00263 & 1912 & 40 \\
\hline \multirow[t]{2}{*}{ NCFS38/16 } & $\# 1450$ & $0 / 34$ & 0,000452 & 0,000012 & 0,11907 & 0,00223 & 0,11211 & 0,00018 & 0,10587 & 0,00019 & 1730 & 3 \\
\hline & $* 1500$ & $0 / 36$ & 0,000136 & 0,000013 & 0,10049 & 0,00103 & 0,11585 & 0,00036 & 0,11398 & 0,00045 & 1864 & 7 \\
\hline \multirow[t]{2}{*}{ NCFS38/18 } & $* 1450$ & $0 / 32$ & 0,000068 & 0,000005 & 0,11354 & 0,00112 & 0,11452 & 0,00032 & 0,11358 & 0,00038 & 1858 & 6 \\
\hline & 1500 & $30 / 30$ & 0,000033 & 0,000005 & 0,09674 & 0,00039 & 0,11527 & 0,00023 & 0,11481 & 0,00021 & 1877 & 3 \\
\hline \multirow[t]{2}{*}{ NCFS38/17 } & $* 1450$ & $0 / 36$ & 0,000137 & 0,000005 & 0,12627 & 0,00228 & 0,11238 & 0,00022 & 0,11035 & 0,00043 & 1806 & 7 \\
\hline & & $98 / 626$ & & & & & & & \multicolumn{4}{|c|}{ Idade Média $=1880 \pm 6 \mathrm{Mc}$} \\
\hline
\end{tabular}


Sabrina Cristina Cordovil Pinho et al.

Tabela 2 - Resultados analiticos Pb-Pb em zircão das amostras NC-GP-52 e NC-GP-49 do MSR.

\begin{tabular}{|c|c|c|c|c|c|c|c|c|c|c|c|c|}
\hline \multicolumn{13}{|c|}{ NC-GP-52 - Maciço Santa Rosa } \\
\hline Zircão & Temperatura & Razões & ${ }^{204} \mathrm{~Pb} /{ }^{206} \mathrm{~Pb}$ & 2 & ${ }^{208} \mathrm{~Pb} /{ }^{206} \mathrm{~Pb}$ & 2 & ${ }^{207} \mathrm{~Pb} /{ }^{206} \mathrm{~Pb}$ & 2 & $\left({ }^{207} \mathrm{~Pb} /{ }^{206} \mathrm{~Pb}\right) \mathrm{c}$ & 2 & Idade & 2 \\
\hline \multirow[t]{2}{*}{ NCGP52/1 } & $\# 1450$ & $0 / 36$ & 0,000502 & 12 & 0,21632 & 67 & 0,12186 & 2 & 0,11508 & 19 & 1882 & 3 \\
\hline & 1500 & $34 / 34$ & 0,000095 & 3 & 0,18927 & 44 & 0,11668 & 27 & 0,11530 & 31 & 1885 & 5 \\
\hline \multirow[t]{2}{*}{ NCGP52/2 } & *1450 & $0 / 14$ & 0,000398 & 18 & 0,15482 & 158 & 0,11942 & 44 & 0,11406 & 51 & 1866 & 8 \\
\hline & 1500 & $8 / 8$ & 0,000000 & 0 & 0,13910 & 46 & 0,11483 & 134 & 0,11483 & 134 & 1878 & 21 \\
\hline \multirow[t]{2}{*}{ NCGP52/3 } & *1450 & $0 / 20$ & 0,000301 & 1 & 0,14043 & 251 & 0,11797 & 29 & 0,11391 & 32 & 1863 & 5 \\
\hline & 1500 & $30 / 30$ & 0,000043 & 6 & 0,11481 & 53 & 0,11583 & 37 & 0,11525 & 34 & 1884 & 5 \\
\hline \multirow[t]{2}{*}{ NCGP52/4 } & $\# 1450$ & $0 / 38$ & 0,000570 & 16 & 0,19271 & 144 & 0,12103 & 26 & 0,11342 & 53 & 1855 & 8 \\
\hline & 1500 & $40 / 40$ & 0,000131 & 9 & 0,17056 & 57 & 0,11726 & 17 & 0,11554 & 15 & 1889 & 2 \\
\hline \multirow[t]{2}{*}{ NCGP52/5 } & ${ }^{*} 1450$ & $0 / 6$ & 0,000092 & 2 & 0,20352 & 591 & 0,11207 & 553 & 0,11082 & 554 & 1813 & 91 \\
\hline & 1500 & $38 / 38$ & 0,000042 & 16 & 0,19038 & 359 & 0,11592 & 56 & 0,11536 & 55 & 1886 & 9 \\
\hline \multirow[t]{3}{*}{ NCGP52/6 } & $* 1450$ & $0 / 16$ & 0,000326 & 12 & 0,16986 & 119 & 0,11762 & 29 & 0,11322 & 33 & 1852 & 5 \\
\hline & *1500 & $0 / 38$ & 0,000245 & 22 & 0,14331 & 76 & 0,11635 & 33 & 0,11317 & 53 & 1851 & 8 \\
\hline & & $150 / 318$ & & & & & & & \multicolumn{4}{|c|}{ Idade média $=1887 \pm 2 \mathrm{Ma}$} \\
\hline \multicolumn{13}{|c|}{ NC-GP-49-Maciço Santa Rosa } \\
\hline Zircão & Temperatura & Razões & ${ }^{204} \mathrm{~Pb} /{ }^{206} \mathrm{~Pb}$ & 2 & ${ }^{208} \mathrm{~Pb} /{ }^{206} \mathrm{~Pb}$ & 2 & ${ }^{207} \mathrm{~Pb} /{ }^{206} \mathrm{~Pb}$ & 2 & $\left({ }^{207} \mathrm{~Pb} /{ }^{206} \mathrm{~Pb}\right) \mathrm{c}$ & 2 & Idade & 2 \\
\hline NCGP49/1 & $* 1500$ & $0 / 34$ & 0,000111 & 14 & 0,20475 & 89 & 0,11598 & 61 & 0,11405 & 72 & 1865 & 11 \\
\hline \multirow[t]{2}{*}{ NCGP49/2 } & 1450 & $22 / 22$ & 0,000288 & 7 & 0,15335 & 104 & 0,11959 & 26 & 0,11573 & 35 & 1892 & 5 \\
\hline & $* 1500$ & $0 / 14$ & 0,000150 & 16 & 0,14930 & 324 & 0,11659 & 36 & 0,11458 & 55 & 1874 & 9 \\
\hline \multirow[t]{2}{*}{ NCGP49/3 } & $* 1450$ & $0 / 8$ & 0,000146 & 2 & 0,12869 & 103 & 0,11785 & 112 & 0,11589 & 115 & 1894 & 18 \\
\hline & 1500 & $38 / 38$ & 0,000108 & 8 & 0,12333 & 33 & 0,11684 & 39 & 0,11538 & 42 & 1886 & 7 \\
\hline NCGP49/4 & $\# 1450$ & $0 / 22$ & 0,001479 & 32 & 0,20606 & 136 & 0,13444 & 5 & 0,11442 & 59 & 1871 & 9 \\
\hline NCGP49/5 & $* 1500$ & $0 / 4$ & 0,000000 & 0 & 0,18165 & 215 & 0,11445 & 28 & 0,11445 & 28 & 1872 & 4 \\
\hline NCGP49/6 & 1450 & $28 / 28$ & 0,000253 & 11 & 0,20807 & 726 & 0,11866 & 19 & 0,11535 & 29 & 1886 & 5 \\
\hline NCGP49/8 & $\# 1450$ & $0 / 4$ & 0,000661 & 18 & 0,22252 & 197 & 0,12226 & 39 & 0,11336 & 46 & 1854 & 7 \\
\hline NCGP49/9 & $* 1450$ & $0 / 36$ & 0,000280 & 5 & 0,18654 & 68 & 0,11772 & 46 & 0,11416 & 47 & 1867 & 7 \\
\hline NCGP49/10 & $\# 1450$ & $0 / 6$ & 0,000808 & 134 & 0,20246 & 467 & 0,12502 & 109 & 0,11415 & 213 & 1867 & 34 \\
\hline NCGP49/11 & 1500 & $32 / 32$ & 0,000072 & 8 & 0,18646 & 115 & 0,11655 & 47 & 0,11558 & 6 & 1889 & 9 \\
\hline \multirow[t]{2}{*}{ NCGP49/12 } & $* 1500$ & $0 / 6$ & 0,000357 & 26 & 0,17786 & 306 & 0,11910 & 102 & 0,11429 & 108 & 1869 & 17 \\
\hline & & $120 / 254$ & & & & & & & \multicolumn{4}{|c|}{ Idade Média $=1888 \pm 3 \mathrm{Ma}$} \\
\hline
\end{tabular}

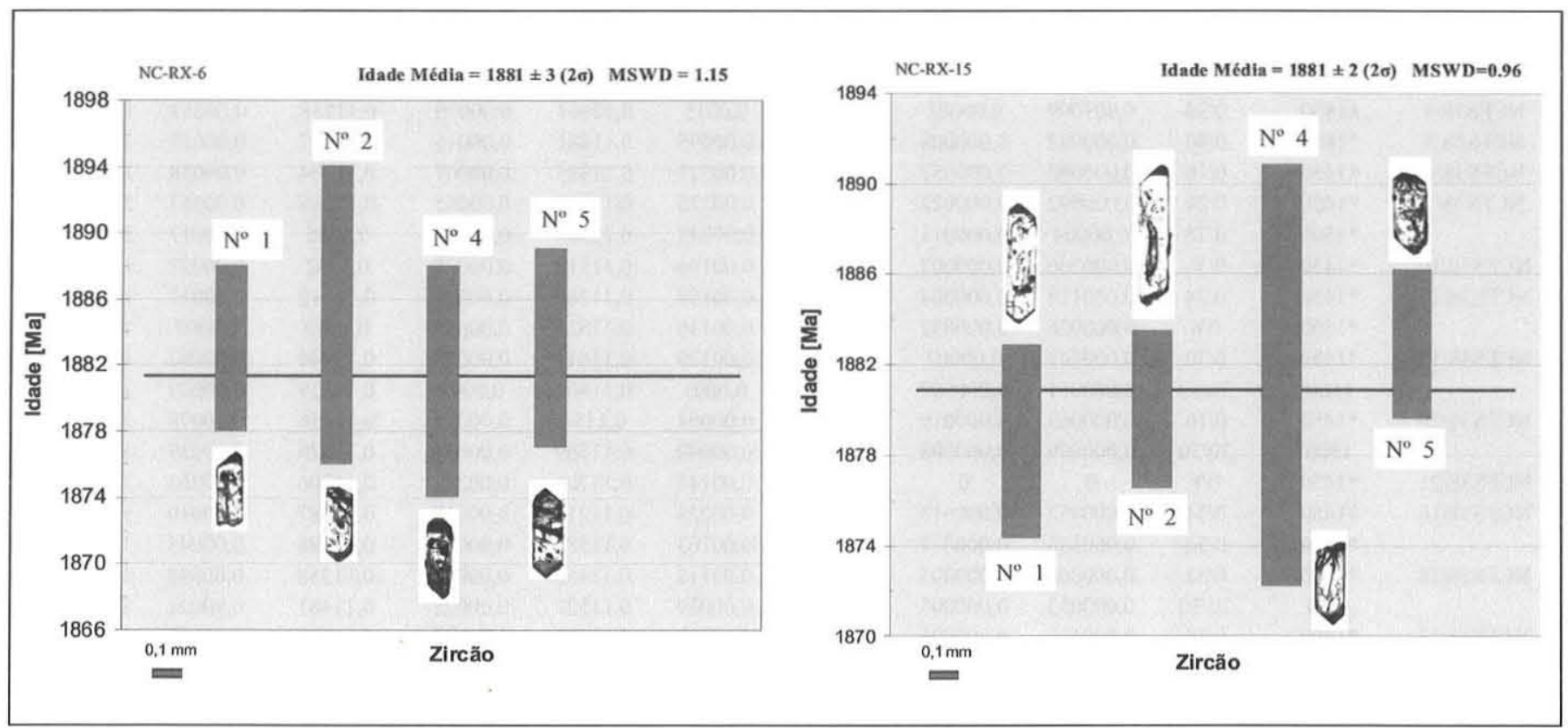

Figura 5-Diagramas de barras mostrando a média das idades dos cristais de zircão analisados das amostras $N C$ - $R X-6$ e NC-RX15 do MPSR. 


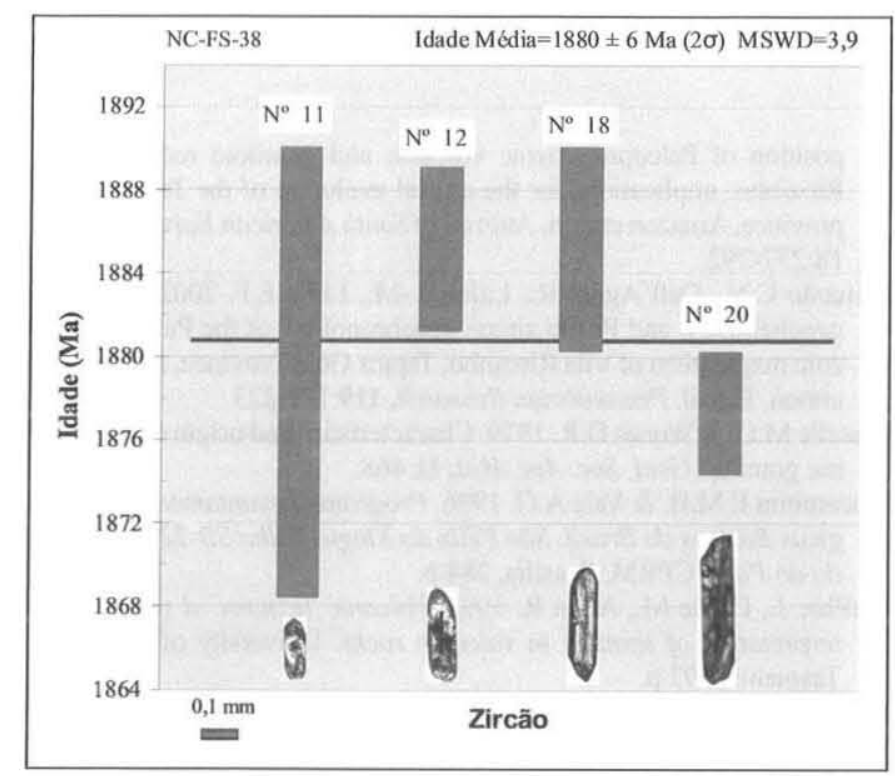

Figura 6 - Diagrama de barras mostrando a média das idades de quatro cristais de zircão de dacito da Formação Sobreiro (amostra NC-FS-38).

grão. Estas médias foram então agrupadas às dos outros dois grãos remanescentes (11 e 18) e forneceram idade média final de $1880 \pm 6 \mathrm{Ma}$ (Figura 6), considerada a idade de cristalização do dacito (Tabela 4). Teixeira et al. 2002a) obtiveram idade de referência $\mathrm{Pb}-\mathrm{Pb}$ em rocha total de $1875 \pm 158 \mathrm{Ma}$ para quatro amostras de andesitos da Formação Sobreiro e dois de riolitos da Formação Iriri. Posteriormente, Teixeira et al. (2002b) realizaram análises $\mathrm{Pb}-\mathrm{Pb}$ em zircão em traquiandesito-basáltico desta unidade e obtiveram idade de $1865 \pm 5$ Ma para apenas um grão e em apenas uma etapa de aquecimento. Estes autores consideraram a existência de apenas um evento vulcânico na região de São Félix do Xingu. Apesar de essas duas datações serem relativamente imprecisas e a segunda apresentar um erro muito elevado, elas se aproximam de certa forma dos dados agora obtidos.

As tentativas de datações dos riolitos da Formação Iriri foram infrutíferas, devido ao avançado estágio de metamictização em que se encontravam os cristais coletados (Fernandes 2005). Durante as análises, os grãos não forneceram sinal de chumbo suficientemente estável. No entanto, como externado anteriormente, relações de campo permitem estender para essa unidade a idade obtida no MSR. Teixeira et al. (2002b) realizaram datações $\mathrm{Pb}$ - $\mathrm{Pb}$ em zircão de riolito e obtiveram idade de $1875 \pm 3$ Ma, para apenas um grão, o que mostra certa correspondência nos resultados.

DISCUSSÃO E CONCLUSÕES A presença de rochas vulcânicas não metamorfisadas associadas a esses três maciços, o freqüente desenvolvimento de intercrescimentos granofíricos, bem como o caráter porfirítico de algumas fácies, sugerem que a colocação ocorreu em profundidades rasas, por vezes em condições subvulcânicas. Nestas condições, a relação cristaislíquido não deveria ser muito elevada quando da colocação dos mesmos (Pitcher 1979). Tais aspectos têm sido verificados em outros granitos anorogênicos ou pós-tectônicos do Cráton Amazônico (Dall'Agnol et al. 1994, Dall'Agnol 1980, Dall'Agnol et al. 1999, Daoud 1988, Gastal 1987, Gonçalez et al. 1988, Lamarão et al. 2002). A variação faciológica identificada nos três maciços é compatível com o modelo de fusão parcial seguida por cristalização fracionada, porém em menor intensidade, pormenorizado por Teixeira et al. (2005) nos maciços Antônio Vicente, Velho Guilherme, Rio Xingu, Mocambo e Ubim/Sul. A ocorrência de dois feldspatos nos granitos dos três maciços, bem como a presença de fluorita, permite enquadrá-los no grupo dos granitos subsolvus (Tuttle \& Bowen 1958), sugerindo a influência de voláteis na temperatura de cristalização do magma gerador. Os trabalhos de detalhe que estão sendo desenvolvidos, tanto geológicos como geoquímicos, permitirão no futuro uma comparação mais completa desses corpos com os outros representantes da Suite Intrusiva Velho Guilherme, contribuindo assim para o entendimento do quadro geodinâmico regional, bem como para a evolução do Cráton Amazônico como um todo.

Fernandes (2005) sugeriu um magmatismo bimodal no Grupo Uatumã, envolvendo a fusão de duas fontes distintas, porém contemporâneas, seguidas por cristalização fracionada independente. Está assertiva está em conformidade com as conclusões de Teixeira (1999), que defendeu a idéia de diferentes fontes para os granitos da Suíte Intrusiva Velho Guilherme, o que explicaria a presença importantes mineralizações em alguns corpos e em outros não. Contudo, novos dados geoquímicos e de química mineral são necessários para uma posição definitiva em relação aos três maciços em estudo, possibilitando assim compará-los com os demais representantes da suíte. A princípio, a evolução dessa associação é interpretada como um misto do que ocorre na região de Vila Riozinho, Província Aurífera do Tapajós, onde Lamarão et al. (2002) caracterizaram uma seqüência cálcico-alcalina de 2000 Ma com assinatura de arco-vulcânico e outra alcalina de $1880 \mathrm{Ma}$ de afinidade geoquímica intraplaca. Contudo, os dados isotópicos de $\mathrm{Nd}$ obtidos por Lamarão et al. 2005) apontam para o envolvimento de fontes crustais proterozóicas na região do Tapajós.

Os dados geocronológicos agora obtidos reforçam idéia de que a região de São Félix do Xingu foi palco, no Paleoproterozóico, de um extenso magmatismo vulcano-plutônico de aproximadamente $1880 \mathrm{Ma}$. Este evento está relacionado à tafrogênese que ocorreu em praticamente todo o Cráton Amazônico (Fernandes 2005, Lamarão et al. 2002, Santos et al. 2000), a qual foi responsável pela geração de depósitos de classe mundial de ouro, estanho, wolframita, molibdenita, criolita, entre outros (Bettencourt et al. 1999, Lamarão et al. 2002, Juliani et al. 2005, Teixeira 1999, Borges et al. 2003). A presença freqüente de cristais herdados de zircão com idade arqueana, como constatado neste estudo, é compatível com os dados isotópicos de $\mathrm{Nd}$ obtidos por Teixeira et al. 2002a) para os granitos Antônio Vicente, Mocambo e Rio Xingu, bem como nas Formações Sobreiro e Iriri, que apontam para fontes crustais dominantemente arqueanas, com idade $\mathrm{T}_{\mathrm{DM}}=3000 \mathrm{Ma}$ e valores de $\varepsilon_{\mathrm{Nd}}$ fortemente negativos, o que permite enquadrar com segurança a região de São Félix do Xingu no núcleo arqueano delimitado pelos dois modelos de Províncias Geocronológicas em vigor para o Cráton Amazônico (Santos et al. 2000, Tassinari \& Macambira 1999).

Agradecimentos Os autores deste trabalho agradecem ao Núcleo PRONEX (103-98/MCT/CNPq-Proc. 66.2103/98-0) do CG/UFPA pelo apoio financeiro nas etapas de campo e na confecção de lâminas petrográficas; ao Laboratório de Geologia Isotópica da UFPa (Pará-Iso) pela realização das análises geocronológicas; ao PIBIC/UFPa pela concessão de bolsa de iniciação científica à Sabrina Cristina Cordovil Pinho, Antônio Lima de Paiva Júnior e Vanessa Lobato Cruz; ao CNPq e ao Curso de Pós-Graduação em Geologia e Geoquímica do CG/UFPA pela concessão de bolsa de mestrado a Carlos Marcello Dias Fernandes; à Prof. Dra Lena Virgínia Soares Monteiro pela revisão do Abstract. Este trabalho é uma contribuição ao projeto PRONEX (103-98/MCT/CNPq-Proc. 66.2103/98-0). 


\section{Referências}

Abreu F.A.M. \& Ramos C.R. 1974. Estanho do Sul do Pará. In: SBG,Congr. Bras. Geol., 28, Porto Alegre, 5, Atas, p. 11-23.

Almeida F.F.M., Hasui Y., Brito Neves B.B., Fuck R.A. 1981. Brazilian structural provinces: An introduction. Earth-Science Reviews, 17:129.

Araújo O.J.B., Maia R.G.N., Jorge João X.S., Costa J.B.S. 1988. A megaestruturação arqueana da folha Serra dos Carajás. In: SBG, Congresso Latinoamericanao de Geologia, 7, Belém, 1, Atas, p. 324-333.

Bettencourt J.S., Tosdal R.M., Leite Jr W.B., Payolla B.L. 1999. Mesoproterozoic rapakivi granites of the Rondonia Tin Province, southwestern border of the Amazonian craton, Brazil - I. Reconnaissance $\mathrm{U}-\mathrm{Pb}$ geochronology and regional implications. Precambrian Research, 95:41-67.

Borges R.M.K., Dall'Agnol R., Costi H.T. 2003. Geologia, petrografia e química mineral das micas dos greisens estaníferos associados ao pluton Água Boa, Pitinga (AM). Revista Brasileira de Geociências, 33:51-62.

Collins W.J., Beams S.D., White A.J., Chapell B.W. 1982. Nature and origin of A. type Granites with particular reference to Southeastern Australia. Contr: Mineral. Petrol., 80:189-200.

Dall'Agnol R. 1980. Etudes sur des granites du type "Rondonian" em Amazonie Orientale et leurs transformations tardi-magmatiques. Tese de Doutoramento, Laboratoire de Geologie, Université Paul Sabatier, Tolouse, $348 \mathrm{p}$.

Dall'Agnol R., Costi H.T., Leite A.A. da S., Magalhaes M.S. de, Teixeira N.P. 1999. Rapakivi granites from Brazil and adjacent areas. Precambrian Research, 95:9-39.

Dall'Agnol R., Lafon J.M., Macambira M.J.B. 1994. Proterozoic anorogenic magmatism in the Central Amazonian Province, Amazonian Craton: geochronological, petrological and geochemical aspects. Mineral. Petrol., 50:113-138.

Daoud W.K. 1988. Granitos estaniferos de Pitinga. Contexto Geológico e depósitos minerais associados. Dissertação de mestrado, Departamento de Geociências, Universidade de Brasília, Brasília, 194 p.

Fernandes C.M.D. 2005. Geologia, Geoquimica e Geocronologia das vulcânicas do Grupo Uatumã, região de São Félix do Xingu (PA), Provincia Mineral de Carajás. Dissertação de Mestrado, Centro de Geociências, Universidade Federal do Pará, Belém, 136 p.

Gastal M.C.P. 1987. Maciço Granítico Musa: Mapeamento, Petrologia e Petroquímica, Rio Maria, SE do Pará. Dissertação do Mestrado, Centro de Geociências, Universidade Federal do Pará, Belém, 327 p.

Gaudette H.E., Lafon J.M., Moura C.A.V., Scheller T. 1993. Datação de monocristais de zircão por evaporação de $\mathrm{Pb}$ no Laboratório de Geologia Isotópica - UFPA; metodologia e primeiros resultados. In: SBG, Congr. Bras. Geoq., 4, Brasília, Atas. p. 236-237.

Gaudette H.E., Lafon J.M., Macambira M.J.B., Moura C.A.V., Scheller T. 1998. Comparison of single filament $\mathrm{Pb}$ evaporation/ionization zircon ages with conventional U-Pb results: examples from the Precambrian of Brazil. Journal of South American Earth Sciences, 11:351-363.

Gonçalez M.G.B., Vieira E.A.T., Dall'Agnol R., Macambira M.J.B., Angelim E.P.V., Senta N.D. 1988. Geologia do Maciço Anorogênico Cigano. Vale do Rio Parauapebas-PA. In: SBG, Congr. Bras. Geol., 35, Belém, 3, Atas. p. 1132-1146.

Juliani C., Rye R.O., Nunes C.M.D., Snee L.W., Correa Silva R.H., Monteiro L.V.S., Bettencourt J.S., Neumann R., Neto A.A. 2005. Paleoproterozoic high-sulfidation mineralization in the Tapajós gold province, Amazonian Craton, Brazil: geology, mineralogy, alunite argon age, and stable-isotope constraints. Chemical Geology, 215: 95-125.

Kober B. 1986. Whole grain evaporation for $207 \mathrm{~Pb} / 206 \mathrm{~Pb}$ age investigations on single zircons using a double filament source. Contributions to Mineralogy and Petrology, 93:482-490.

Kober B. 1987. Single grain evaporation combined with $\mathrm{Pb}+$ emitter bedding for $207 \mathrm{~Pb} / 206 \mathrm{~Pb}$ investigations using thermal ion mass spectrometry, and implications for zirconology. Contributions to Mineralogy and Petrology, 96:63-71.

Lamarão C.N., Dall'Agnol R., Pimentel M.M. 2005. Nd isotopic com- position of Paleoproterozoic volcanic and granitoid rocks of Vila Riozinho: implications for the crustal evolution of the Tapajos gold province, Amazon craton. Journal of South American Earth Sciences, 18:277-292.

Lamarão C.N., Dall’Agnol R., Lafon J.-M., Lima E.F. 2002. Geology, geochemistry, and $\mathrm{Pb}-\mathrm{Pb}$ zircon geochronology of the Paleoproterozoic magmatism of Vila Riozinho, Tapjos Gold Province, Amazonian craton, Brazil. Precambrian Research, 119:189-223.

Loiselle M.C. \& Wones D.R. 1979. Characteristics and origin of anorogenic granites. Geol. Soc. Am. Abst, 11:468.

Macambira E.M.B. \& Vale A.G. 1996. Programa Levantamentos Geológicos Básicos do Brasil. São Félix do Xingu. Folha SB-22-Y-B. Estado do Pará. CPRM, Brasília, 384 p.

McPhie J., Doyle M., Allen R. 1993. Volcanic Textures: A guide to interpretation of textures in volcanic rocks. University of Tasmania, Tasmania, $197 \mathrm{p}$.

Pearce J.A., Harris N.B.W., Tindle A.C. 1984. Trace Elements discrimination diagrams for the tectonic interpretation of granitic rocks. $J$. Petrol., 25:956-983.

Pitcher W.S. 1979. The nature, ascent and empacement of granitic magmas. Geology, 136:627-662.

Santos J.O.S., Hartmann L.A., Gaudette H.E., Groves D.I., McNaughton N.J., Fletcher I.R. 2000. A New Understanding of the Provinces of the Amazon Craton Based on Integration of Field Mapping and U-Pb and Sm-Nd Geochronology. Gondwana Research, 3:453-488.

Smith J.V. \& Brown W.L. 1988. Feldspar minerals. Springer-Verlag, Berlin, $828 \mathrm{p}$.

Stacey J.S. \& Kramers J.D. 1975. Approximation of terrestrial lead isotope evolution by a two-stage model. Earth and Planetary Science Letters, 26:207-221.

Streckeisen A. 1976. To each plutonic rocks its proper name. Earth Sci. Rev., 12:1-33.

Tassinari C.C.G. \& Macambira M.J.B. 1999. Geochronological Provinces of the Amazonian Craton. Episodes, 22:174-182.

Teixeira N.P. 1999. Contribuição ao estudo das rochas granitóides e mineralizações associadas da Suite Intrusiva Velho Guilherme, Provincia Estanifera do Sul do Pará. Tese de Doutoramento, Instituto de Geociências, Universidade de São Paulo, São Paulo, 508 p.

Teixeira N.P., Bettencourt J.S., Dall'Agnol R., Moura C.A.V., Fernandes C.M.D., Pinho S.C.C. 2005. Geoquímica de granitos Paleoproterozóicos da Suíte Intrusiva Velho Guilherme, Província Estanífera do Sul do Pará. Revista Brasileira de Geociências, 35:217-226.

Teixeira N.P., Bettencourt J.S., Moura C.A.V., Dall'Agnol R. 1998. Pb-Pb and Sm-Nd constraints of the Velho Guilherme Intrusive Suite and volcanic rocks of the Uatumã Group. South-Southeast Pará-Brazil. In: IGCP, Project 426. Granite Systems and Proterozoic Lithospheric Processes. Madison, v.1. p. 178-180.

Teixeira N.P., Bettencourt J.S., Moura C.A.V., Dall'Agnol R., Macambira E.M.B. 2002a. Archean crustal sources for Paleoproterozoic tin-mineralized granites in the Carajas Province, SSE Para, Brazil: $\mathrm{Pb}-\mathrm{Pb}$ geochronology and Nd isotope geochemistry. Precambrian Research, 119:257-275.

Teixeira N.P., Fernandes C.M.D., Moura C.A.V., Pinho S.C.C., Bettencourt J.S. 2002b. Geologia, Geoquímica, Geocronologia e isótopos de Sm-Nd de rochas vulcânicas paleoproterozóicas do Grupo Uatumã ocorrentes na região de São Félix do Xingu, Província Mineral de Carajás, Cráton Amazônico, Brasil. In: SBG, Simpósio sobre Vulcanismo e Ambientes Associados, 2, Belém, Boletim de Resumos e Roteiro da Excursão, p. 28

Tuttle O.F. \& Bowen N.L. 1958. Origin of granite in the light of experimental studies in the system NaAlSi3O8-SiO2-H2O. Memoir, $153 \mathrm{p}$.

Manuscrito AE042

Aprovado em 30 de outubro de 2006 